\title{
The reading of Passive UHF Tags by RFID Technology Using Various Combinations of Antennas Motorola AN480
}

\author{
Petra Juránková \\ Department of Transport Management, Marketing and \\ Logistics, Jan Perner Transport Faculty, University of \\ Pardubice, Pardubice, Czech Republic \\ petra.jurankova@student.upce.cz
}

\begin{abstract}
The article deals with the measurement of the accuracy of the reading of passive UHF tags (ALN-9640, ALN9654, ALN-9662 and ALN-9629 from the company Alien) located on postal crates through RFID technology using various combinations of antennas Motorola AN480. The aim of the measurement was to compare the accuracy of the reading each tag and evaluate the utilization of individual antennas while loading tags under each option of using antennas. The measured results showed that the best reading accuracy was achieved with the involvement of only one antenna placed over the scanned postal crates compared to variant of the reading through side antennas or even all three antennas.
\end{abstract}

Keywords-RFID technology; passive UHF tag; antenna; postal crate; transport cage.

\section{INTRODUCTION}

RFID technology (Radio Frequency Identification) is part of automatic identification and is becoming a modern trend of identification in many sectors (e. g. the identification of goods in retail, of manufacturing parts in the automotive industry or of manipulation means by foreign postal operators). The information is stored in the tag electronically. The tag stores a unique identification number and next information is associated with the product subsequently. Then the tags retrieve information using radio waves. This process doesn't happen after each reading as with barcodes, but in bulk. The current readers of RFID technology can simultaneously reading up to several hundred tags per minute. [1] [2]

Postal crate is a transport unit which is used for transportation and handling of items of correspondence between one or more departments of postal operator. In the process of transportation of the postal crate can be considered as the lowest level of the transport unit. [3] [4]

Transport cage is a transportation unit, which serves to transport and to store consignments of packages, correspondence, newspapers etc. (capacity is $500 \mathrm{~kg}$ ). The transport takes place from post offices or sending collecting transport nodes through rail and road courses into processing centers. [5]

\section{THE RFID SYSTEM For MEASUREMENT}

The RFID system contains these basic elements:

- Working terminal (notebook),

\author{
Libor Švadlenka
}

Department of Transport Management, Marketing and Logistics, Jan Perner Transport Faculty, University of Pardubice, Pardubice, Czech Republic libor.svadlenka@upce.cz

- Connecting cables,

- Reader Motorola FX9500 - 4-port fixed reader,

- 3 pes of antenna Motorola AN480,

- 9 pcs of UHF (Ultra High Frequency) tags ALN9640 ,

9 pcs of UHF tags ALN-9654,

9 pcs of UHF tags ALN-9662,

9 pes of UHF tags ALN-9629.

Fig. 1 shows the location of UHF tags on individual postal craters, wherein each tag was attached to the upper part of the postal crate.

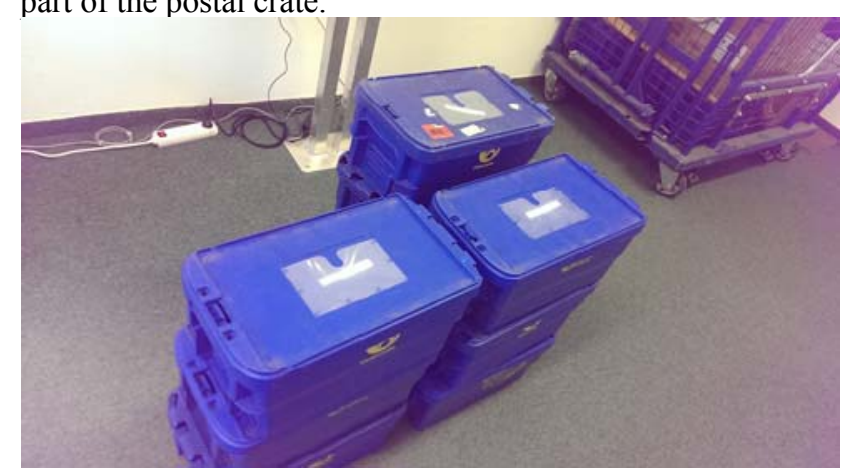

Figure 1 - The location of UHF tags on postal craters

The location of 9 pes of postal crates to the transport cage for measurement of their numerical designation, which also applies to individual tags, can be seen in Fig. 2.

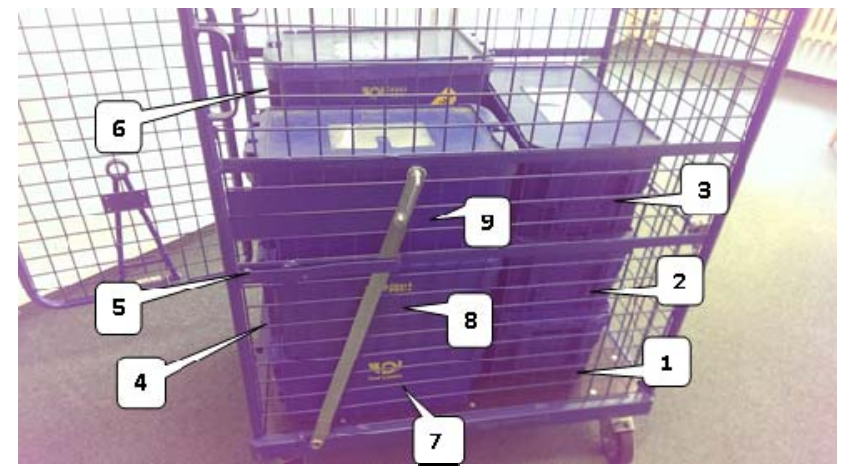

Figure 2. - The location of postal crates to the transport cage 


\section{THE MEASUREMENT}

The three antennas were used within the measurement. The measurement is implemented in three variants. In the first variant, 9 passive UHF tags were read by all 3 antennas of Motorola AN480. The second variant, only two lateral antennas (antenna 1 and antenna 3) was used and in the third variant one antenna (the upper - antenna 2) is used. At each variant 50 measurements were realized that means 600 measurements. The retrieving time was 5 seconds. The measurement was performed by program Session One from Motorola.

\section{The Results Of Measurement}

This chapter deals with the interpretation of results at each variations of the measurement. The aim is to compare the accuracy of the individual retrieving of tags that have been placed on the postal crates in the transport cage, as shown in Fig. 2. Furthermore, the utilization of individual antennas is evaluated while the tags are reading during of each variant.

\section{A. The first measurement}

In the first measurement, passive UHF tags ALN-9640 were used. It showed that the most widely reading tag is the tag 9 (green-labeled in TABLE I for variations of 2 and 1 antenna), which was first right on the postal crate. This tag reached the maximum number of reading (7 810) in the second variant (reading of 2 antennas). The least reading tag is the tag 5 (red-labeled in TABLE I for variations of 3 and 2 antennas) in two variants. The tag 5 was in the second column in the middle on the postal crate and it reached the lowest number of reading (1600) in the second variation. The summary results shows TABLE I for the first measurement.

TABLE I - The total number of load of each tag in the first measurement

\begin{tabular}{|c|c|c|c|c|}
\hline \multicolumn{2}{|r|}{ Tag } & The number of & The number of & $\begin{array}{l}\text { The number of } \\
\text { read ( } 1 \text { antenna) }\end{array}$ \\
\hline 1. & E200900017180029173064E2 & 4130 & 1970 & 6780 \\
\hline 2. & E2009000171800291700658F & 4960 & 3450 & 8400 \\
\hline 3. & E200900017180029174064E3 & 5300 & 6690 & 5110 \\
\hline 4. & E200900017180029172064E1 & 7060 & 7650 & 5020 \\
\hline 5. & E20090001718002917805CC3 & 2600 & 1600 & 4130 \\
\hline 6. & E20090001718002917705CC2 & 6050 & 4070 & 9090 \\
\hline 7. & E20090001718002917106590 & 5750 & 6340 & 4660 \\
\hline 8. & E20090001718002917605CC1 & 5330 & 5470 & 4800 \\
\hline 9. & E2009000171800291690658E & 5480 & 7810 & 3920 \\
\hline
\end{tabular}

For a better overview Fig. 3 illustrates the values in TABLE I graphically in percentage.

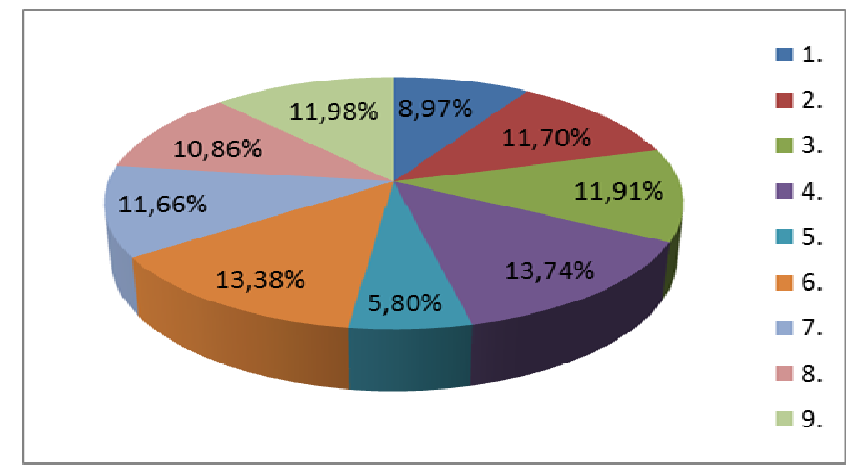

Figure 3. - The load of each tag within the first measurement

The survey of the first measurement shows that the most widely reading tag is the tag 4 and the least reading tag is the tag 5 .

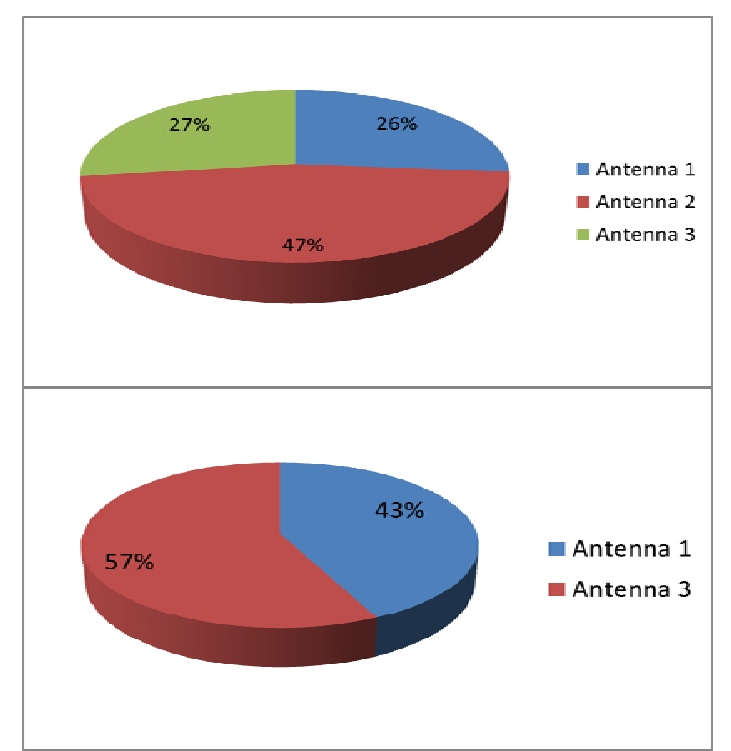

Figure 4. - The percentage of utilization of the individual antennas (1 and 2 variations)

From Fig. 4 it's seen, that the most reading conducted antenna is antenna 2 (upper antenna) and is about $50 \%$ of the total reading (21 735 reads). In the second variant (reading of the antennas 1 and 3), the antenna 3 was read more (by $14 \%$ - 6356 reads).

From the comparison of the total reading at individual variants follows that 46663 tags were read in the first variant, 45058 tags were read in the second variant and 51911 tags were read in the third variant.

\section{B. The second measurement}

In the second measurement, passive UHF tags ALN9654 were used. It showed that the most widely reading tag is the tag 4 (green-labeled in TABLE II for variations of 3 and 2 antennas), which was bottom left on the postal crate. This tag reached the maximum number of reading (7 570) in the second variant (reading of 2 antennas). In this 
measurement doesn't exist tag as in the first measurement, which would be the worst read in more than one variant. In the first variant is the tag 1 , in the second variant is the tag 9 and in the third variant is the tag 2 . From these three tags was the worst read tag 9 (1 200 reading). The summary results show TABLE II for the second measurement.

TABLE II - The total number of load of each tag in the second measurement

\begin{tabular}{|c|c|c|c|c|}
\hline \multicolumn{2}{|r|}{ Tag } & The number of & The number of & The number of \\
\hline 1. & E2002064870D0085127094F3 & 3630 & 2500 & 5140 \\
\hline 2. & E2002064870D00850900B8A2 & 5960 & 6140 & 3510 \\
\hline 3. & E2002064870D00850920B8A4 & 4850 & 3640 & 4340 \\
\hline 4. & E2002064870D00851020AE6E & 6890 & 7570 & 6990 \\
\hline 5. & E20090024814003714308844 & 6330 & 5490 & 7280 \\
\hline 6. & E2009002481400371390893C & 4880 & 6030 & 3620 \\
\hline 7. & E20090024814003714708060 & 6710 & 7250 & 6550 \\
\hline 8. & E2009002481400371450805E & 6560 & 6910 & 5690 \\
\hline 9. & E20090024814003714108842 & 3790 & 1200 & 5790 \\
\hline
\end{tabular}

For a better overview Fig. 5 illustrates the values in TABLE II graphically in percentage.

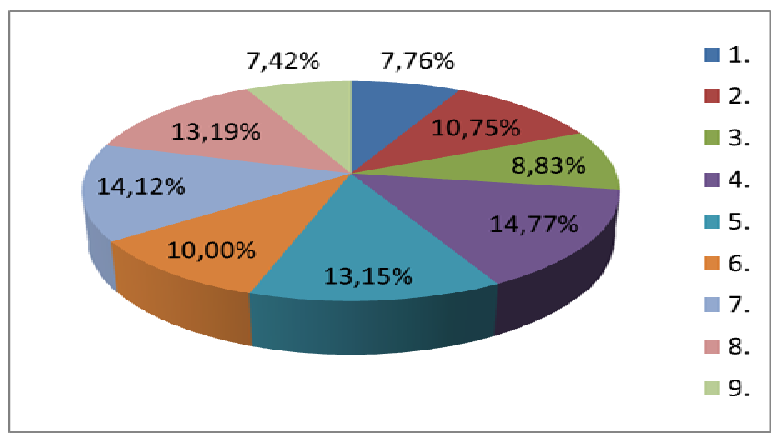

Figure 5-The load of each tag within the second measurement

The survey of the second measurement shows that the most widely reading tag is the tag 4 and the least reading tag is the tag 9 .

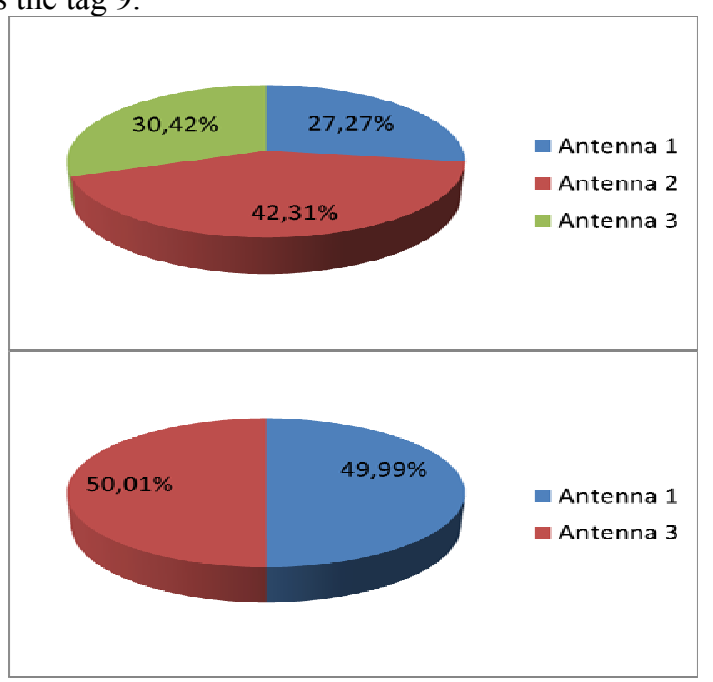

Figure 6 - The percentage of utilization of the individual antennas ( 1 and 2 variations)
From Fig. 6 it's seen that most reading conducted antenna is antenna 2 (upper antenna) and is about $43 \%$ of the total reading $(20145)$. In the second variant are numbers of reading of both antennas completely balanced, antenna 1 had reading 23365 tags and antenna 3 had reading 23372 tags. The difference is only 7 tags, which it's a slight difference.

From the comparison of the total reading at individual variants follows that 47609 tags were read in the first variant, 46676 tags were read in the second variant and 48917 tags were read in the third variant.

\section{The third measurement}

In the third measurement, passive UHF tags ALN-9662 were used. It showed that doesn't exist tag as in the previous measurements, which would be the most widely read in more than one variant. The tag 7 is in the first variant, the tag 6 is in second variant and the tag 4 is in third variant. From these three tags was the best reading tag 4 (7 370). The opposite situation is with the worst read tag, the tag 2 is the worst reading tag and in all variants. The worst was read in the second variation, when the number of reading was 2390 . Summary results show TABLE III for the third measurement.

TABLE III - The total number of load of each tag in the third measurement

\begin{tabular}{|c|c|c|c|c|}
\hline \multicolumn{2}{|r|}{ Tag } & $\begin{array}{l}\text { The number of } \\
\text { read ( } 3 \text { antennas) }\end{array}$ & $\begin{array}{c}\text { The number of } \\
\text { read (2 antennas) }\end{array}$ & $\begin{array}{l}\text { The number of } \\
\text { read (1 antenna) }\end{array}$ \\
\hline 1. & E2001994940A026416606676 & 5520 & 5370 & 6590 \\
\hline 2. & E2001994940A02781660663E & 3090 & 2390 & 2650 \\
\hline 3. & E2001994940A02221650671D & 5490 & 5420 & 6060 \\
\hline 4. & E2001994940A0247165066B9 & 5890 & 5590 & 7370 \\
\hline 5. & E2001994940A028016606636 & 6120 & 6150 & 7220 \\
\hline 6. & E2001994940A0241166066D2 & 6360 & 7350 & 5290 \\
\hline 7. & E2001994940A026116506681 & 6670 & 7240 & 5800 \\
\hline 8. & E2001994940A02551660669A & 4910 & 4310 & 5550 \\
\hline 9. & E2001994940A025716606692 & 4980 & 5300 & 5400 \\
\hline
\end{tabular}

For a better overview Fig. 7 illustrates the values in TABLE III graphically in percentage.

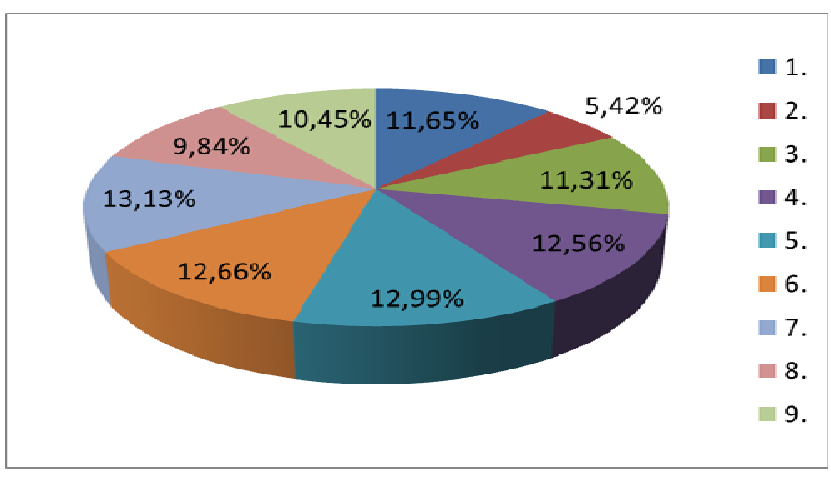

Figure 7 -The load of each tag within the second measurement

The survey of the third measurement shows that the most widely reading tag is the tag 7 and the least reading tag is the tag 2 . 


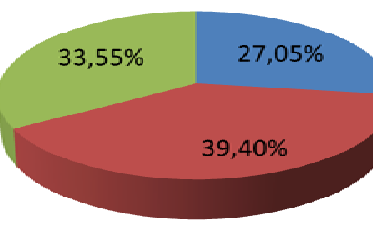

- Antenna 1

antenna 2

Entenna 3

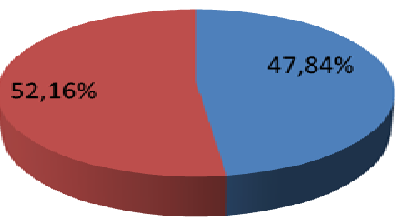

antenna 1

Antenna 3

Figure 8 - The percentage of utilization of the individual antennas ( 1 and 2 variations)

From Fig. 8 it's seen that most reading conducted antenna is antenna 2 (as in the previous measurements) and is about $40 \%$ of the total reading (19 338). As with the first measurement antenna 3 had reading more tags (about $5 \%$ 2124 reading).

From the comparison of the total reading at individual variants follows that 49063 tags were read in the first variant, 49120 tags were read in the second variant and 48912 tags were read in the third variant.

\section{The fourth measurement}

In the fourth measurement, passive UHF tags ALN9629 were use. It showed that the most widely reading tag is the tag 8 (green-labeled in TABLE IV for variations of 3 and 1 antenna). This tag reached the maximum number of reading (11 490) in the third variant. The least reading tag is the tag 1 (red-labeled in TABLE IV for variations of 3 and 2 antennas) in two variants. The tag 1 was in the bottom row on the side on the postal crate and it reached the lowest number of reading (only 160 and is the lowest number of reading in all measurements) in the second variation. In this measurement wasn't read some tags, specifically the tags 1 , 6 and 9. From a total of 150 measurements wasn't reading tag 1 in a total of 92 measurements, tag 6 wasn't reading in a total of 63 measurements and tag 9 wasn't reading in a total of 33 measurements. Summary results show Fig. 12 for the fourth measurement.
TABLE IV - THE TOTAL Number Of LOAD OF EACH TAG IN THE FourTH MEASUREMENT

\begin{tabular}{|c|c|c|c|c|}
\hline \multicolumn{2}{|c|}{ Tag } & $\begin{array}{c}\text { The number of } \\
\text { read (3 antennas) }\end{array}$ & $\begin{array}{c}\text { The number of } \\
\text { read (2 antennas) }\end{array}$ & $\begin{array}{c}\text { The number of } \\
\text { read (1 antenna) }\end{array}$ \\
\hline $\mathbf{1 .}$ & E200900257010071187054B4 & $\mathbf{9 3 0}$ & $\mathbf{1 6 0}$ & $\mathbf{3 1 5 0}$ \\
\hline $\mathbf{2 .}$ & E20090025701007121903374 & $\mathbf{1 6 2 0}$ & $\mathbf{1 4 5 0}$ & $\mathbf{4 5 2 0}$ \\
\hline $\mathbf{3 .}$ & E200900257010071212039DD & $\mathbf{3 4 6 0}$ & $\mathbf{1 8 3 0}$ & $\mathbf{4 0 3 0}$ \\
\hline $\mathbf{4 .}$ & E200900257010071220031FD & $\mathbf{4 3 3 0}$ & $\mathbf{8 0 0}$ & $\mathbf{6 3 0 5 0}$ \\
\hline $\mathbf{5 .}$ & E200900257010071146080CF & $\mathbf{1 6 1 0}$ & $\mathbf{1 1 3 0}$ & $\mathbf{3 0 3 0}$ \\
\hline $\mathbf{6 .}$ & E200900257010071188052D1 & $\mathbf{3 1 5 0}$ & $\mathbf{2 ~ 7 0 0}$ & $\mathbf{1 3 0 0}$ \\
\hline $\mathbf{7 .}$ & E20090025701007118005B79 & $\mathbf{3 8 9 0}$ & 5210 & $\mathbf{8 3 4 0}$ \\
\hline $\mathbf{8 .}$ & E20090025701007121103B74 & 9860 & $\mathbf{5 0 7 0}$ & 11490 \\
\hline $\mathbf{9 .}$ & E20090025701007117905D6C & $\mathbf{1 1 6 0}$ & $\mathbf{4 7 0}$ & $\mathbf{6 5 2 0}$ \\
\hline
\end{tabular}

For a better overview Fig. 9 illustrates the values in TABLE IV graphically in percentage.

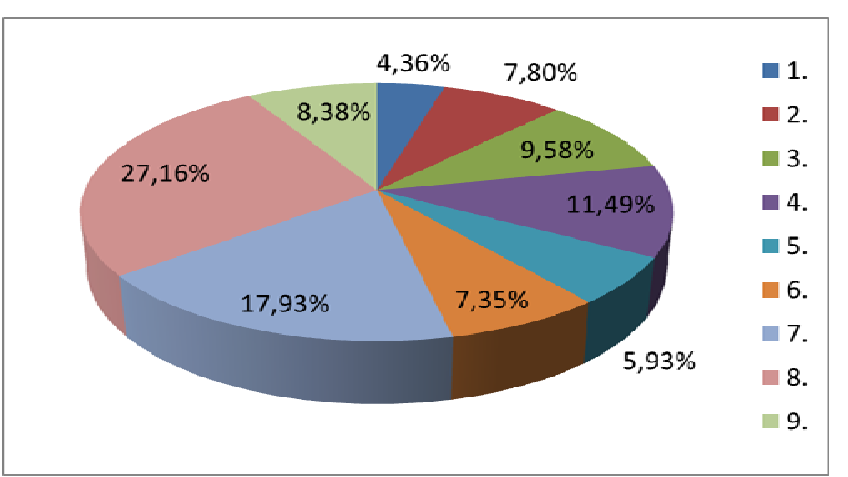

Figure 9 -The load of each tag within the second measurement

The survey of the fourth measurement shows that the most widely reading tag is the tag 8 and the least reading tag is the tag 1 .

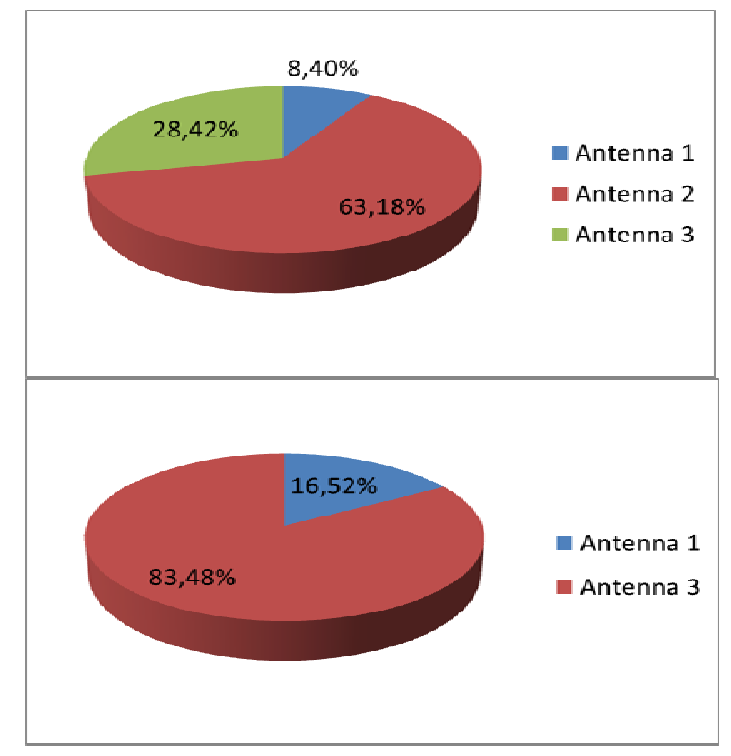

Figure 10 -The load of each tag within the second measurement

From Figure 10 it's seen that most read conducted antenna is antenna 2 (as in the previous measurements but 
with a greater ratio) and is about $63 \%$ of the total loading (18 965 reading). At least tags had reading antenna 1 and only 2520 tags (antenna $2-8536$ tags). In this measurement (in the second variant) it's possible to see the biggest difference between the number of read tags with antenna 1 and antenna 3, where the antenna 1 had read 3117 tags (about $17 \%$ ) and antenna 3 had read 15711 tags (about $83 \%$ ).

From the comparison of the total reading at individual variants follows that 30015 tags were read in the first variant, 18828 tags were read in the second variant and 48750 tags were read in the third variant.

\section{THE CONCLUSION}

These measurements show that when compared numbers of reading of each tag, the most reading tag is tag 8 and a whole 75950 reads. The worst reading tag is tag 1 with a total value of 45870 reads. The difference between these tags is 30080 reads.

When comparing the total number of reading between the various tapes of the passive UHF RFID tags from company Alien has been found that the most read tag was type ALN-9662 (150 0850 reads). This inlay type (as well as others used tags) is useful for identifying of pallets or for application on plastics. The worst read type of tags was type ALN-9629 (97 260 reads) and moreover weren't reading all tags (see the fourth measurement). This type was an experiment whether tags, that are suitable for identification of clothing or pharmaceutical products is also suitable for identification of plastic crates. As it turned out, is inappropriate.

These measurements also shows that the best values of the number of reading of tags within 5 seconds reached the third option, when has been activated only the upper antenna. The exception is the third measurement, when the better value reached the second variant (two antennas), but only about 208 reads. The worst variant from the same perspective it's second variant (side antennas) except for the third measurement, when the difference is negligible only 57 reads. It follows that isn't need of connecting of more antennas, but is sufficient connect of two upper antennas when the second upper antenna could also serve as a backup if in the first antennas has occurred the fault and it would be necessary to ensure continuous reading.

These measurements will be the basic for further measurements, when these data will be compared with other options. For example: how will be different the number of reading tags with different combinations of antennas involved in the case of full postal crates, which should more accurately simulate real operation. It will further investigate how the number of reading tags will be changed if they weren't placed tags behind the plastic cover, but for example on the sides of postal crates, mainly due to reading of side antennas.

\section{ACKNOWLEDGMENT}

This article was created within the project "Innovation of subjects Technology and Control of Postal Operations of field of study MEKPS and Logistics I of field of study DMML using the system for data collection and analysis, no : IRS2015 / 050 ".

The article was published with the support of Student Grant Competition of University Pardubice, the project number: 51030/20 / SG550001. The authors are grateful for the support.

\section{REFERENCES}

[1] SWEENEY II, Patrick J., 2005. RFID for Dummies. Indiana: Wiley Publishing, Inc. ISBN 978-0-7645-7910-3.

[2] PRERADOVIC, Stevan a Nemai Chandra KARMAKAR, 2012. Multiresonator-based chipless RFID: barcode of the future. New York: Springer, 170 p. ISBN 978-1-4614-2094-1.

[3] TENGLER, Jiří, Ondrej MASLÁK a Juraj VACULÍK, 2012. The influence of the construction of the postal container on readability of RFID tag placed on postal crates. In: Day of new Technologies DoNT 2012 collection of papers and lectures of the conference with international participation. Žilina: University of Žilina, p. 141-148. ISBN 978-80-554-0600-8.

[4] VACULÍK, Juraj, Peter KOLAROVSZKI a Jiří TENGLER, 2012. Results of automatic identification of transport units in postal environment. In: Transport and telecommunication. p. 75-87. ISSN 1407-6160.

[5] ŠVADLENKA, Libor, Daniel SALAVA a Daniel ZEMAN, 2013. Technique and technology of processing of postal items. Edition 1. Pardubice: University of Pardubice, 186 s., ISBN 978-80-7395-727-8. 